\title{
Current anthelmintic treatment is not always effective at controlling strongylid infections in German alpaca herds
}

Luise Kultscher ${ }^{1}$, Barbara Hinney ${ }^{2}$, Ronald Schmäschke ${ }^{3}$, Anja Joachim² ${ }^{2 *}$ and Thomas Wittek ${ }^{1 \dagger}$

\begin{abstract}
Background: Endoparasites are considered a major health problem of South American camelids as shown in a recent survey among German and Austrian camelid owners. Although prophylactic and therapeutic measures such as application of anthelmintics are commonly used, treatment efficacy is usually not assessed. Owners have expressed significant concerns regarding the effect of antiparasitic therapy, so this study aimed to evaluate the outcome of anthelmintic treatment in German alpaca herds with different drugs.

Results: Overall, 617 samples from 538 clinically healthy alpacas $>1$ year-old from 27 farms $(n=11-157$ animals/ herd) were examined. The most common parasites detected by flotation were Eimeria spp. (75.1\%) followed by strongylids (55.0\%), Nematodirus spp. (19.3\%), cestodes (3.1\%) and Trichuris (2.7\%). After initial coproscopical examination by flotation and strongylid egg quantification by the McMaster technique, positive animals excreting at least 150 eggs per gram of faeces were included in a faecal egg count reduction test (FECRT) using fenbendazole ( $n=71$ samples), moxidectin $(n=71)$ or monepantel $(n=66)$. Pre-treatment larval cultures ( $n=23$ positive pooled farm samples) revealed Haemonchus (87\% of the farms), Cooperia (43.5\%), Trichostrongylus (21.7\%), Ostertagia (13.0\%), Nematodirus and Oesophagostomum (4.3\% each). Fenbendazole treatment reduced egg excretion by $45 \%$, moxidectin by $91 \%$ and monepantel by $96 \%$. On the farm level, $13 / 18$ farms that used fenbendazole, $6 / 6$ farms that used moxidectin and 2/5 farms that used monepantel had individual FECR values $<90 \%$ (fenbendazole) or $<95 \%$ (moxidectin, monepantel). Haemonchus and Cooperia were overrepresented on the farms with reduced treatment efficacy.

Conclusions: Gastrointestinal strongylids are common in German alpacas and fenbendazole in particular was not sufficiently effective to reduce strongylid egg excretion. Although the FECRT could not unambiguously determine anthelmintic resistance in the present study, the finding that small ruminant strongylids, especially Haemonchus, are common in alpacas indicates that determination of effective anthelmintic doses, monitoring of efficacy and adapted (selective) treatment regimens must be implemented as part of sustainable deworming practices in this species in accordance with recommendations for ruminants.
\end{abstract}

Keywords: South American camelids, Efficacy, Nematodes, Haemonchus contortus, Fenbendazole, Moxidectin, Monepantel

\footnotetext{
*Correspondence: Anja.Joachim@vetmeduni.ac.at

${ }^{\dagger}$ Anja Joachim and Thomas Wittek contributed equally to this work

2 Institute of Parasitology, Department of Pathobiology, University

of Veterinary Medicine Vienna, Veterinärplatz 1, 1210 Wien, Austria

Full list of author information is available at the end of the article
}

(c) The Author(s) 2019. This article is distributed under the terms of the Creative Commons Attribution 4.0 International License (http://creativecommons.org/licenses/by/4.0/), which permits unrestricted use, distribution, and reproduction in any medium, provided you give appropriate credit to the original author(s) and the source, provide a link to the Creative Commons license, and indicate if changes were made. The Creative Commons Public Domain Dedication waiver (http://creativecommons.org/ publicdomain/zero/1.0/) applies to the data made available in this article, unless otherwise stated. 


\section{Background}

South American camelids are becoming increasingly popular outside their native habitat [1-3]. In Germany, an estimated 20,000 alpacas are kept for a variety of purposes, including wool production (77\%) and trekking (29\%), and less frequently for animal-assisted therapy (12\%), landscape management (3\%) or simply as pets [4].

So far, only few published data are available regarding the endoparasites of these animals in their new environment and the pharmacological control options $[5,6]$. In central Europe, information on camelid endoparasites is available for southern and central Germany [7-9], and, as a more comprehensive study, for Austria [10], all demonstrating a range of endoparasites, especially coccidia and strongylid nematodes, with variable but often high prevalence rates. Recently, a survey questioning owners of alpacas in Germany and Austria showed that endoparasites were regarded as a major problem in the herds and are diagnosed frequently $(78.6 \%$ herd prevalence for gastrointestinal nematodes and $73.3 \%$ for coccidia; [4]). Prophylactic and therapeutic measures (including anthelmintic treatment with moxidectin as the most commonly used drug, followed by fenbendazole and monepantel, and consecutive treatment with different anthelmintics) are frequently applied. However, the effect of the treatment is not evaluated systematically (e.g. by post-treatment faecal examinations) and owners have expressed considerable concern about poor treatment efficacy, albeit without reliable data to support this view [4]. Larger farms in particular have reported cases of fatalities due to endoparasites of small ruminants, most commonly infections with Haemonchus contortus, the Barber's pole worm [4].

After the first case report of ivermectin resistance of $H$. contortus in an alpaca herd in Australia [11], a recent systematic study described resistance to several anthelmintics (ivermectin, moxidectin, fenbendazole, closantel) in strongylids of Australian alpacas [12]. The large Australian sheep population may have contributed to the transfer of resistant nematodes to alpacas [12] since cross-transmission of a number of strongylid species (including $H$. contortus) between these hosts is common [13]. In Europe, resistance to doramectin has been reported on a Belgian alpaca farm and confirmed in a controlled field trial, and the main strongylid species involved was $H$. contortus [14].

We wanted to obtain an overview on the prevalence of endoparasites in the alpaca population in Germany and possible geographical variations, and determine whether the anthelmintic treatment commonly applied in the investigated herds is sufficient to control strongylid nematodes. For this purpose we conducted a follow-up study based on the previous questionnaire survey where
German alpaca owners were asked to participate in faecal examinations of their animals [4]. Based on the survey results we hypothesized that commonly applied anthelmintics showed a decreased efficacy in alpacas in Germany. It was also assumed that $H$. contortus is common and plays an important role in the alpaca population.

\section{Methods}

\section{Selection of animals and farms}

The selection of the participating farms was based on a questionnaire on endoparasitoses [4] which provided general information on herd size, management, feeding, housing, environmental conditions, hygiene and the purpose of the animals. Specific veterinary aspects of the survey included results of previous faecal examinations, frequently diagnosed endoparasites, the owners' perception of the current status of anthelmintic efficacy, deworming management and diseases and losses caused by endoparasitoses [4].

In this questionnaire, the breeders were also asked if they would be willing to contribute to a study exploring the efficacy of commonly used antiparasitic drugs. A further selection criterion for the participating farms was the anthelmintic drug predominately used in the herd. Since the study aimed to test the efficacy of three different drug groups (benzimidazoles, macrocyclic lactones and aminoacetonitriles), approximately equal numbers of farms using these drug classes were enrolled in the study.

The enrolled alpacas were older than one year, clinically healthy, of different sexes and had not been treated with anthelmintics for at least 12 weeks before the first sampling. Only medium-sized (11-50 animals) and largesized herds (51-157 animals) were examined. From each farm, inclusion of at least 20 animals was intended; if this was not possible, repeated sampling was undertaken.

The final selection of the included farms was also based on consideration of the geographical distribution aiming to include farms from different regions of Germany (Table 1).

\section{Faecal examinations}

Individual faecal samples were collected at the beginning of the study and transferred to the laboratory on the same day. Faecal consistency was scored from 1 (physiological) to 4 (semi-liquid). Upon arrival, faeces were examined for the presence of parasitic stages by a combined sedimentation-flotation method. A walnut-sized piece of faeces was homogenized with water, sieved and transferred to a centrifugation tube. After centrifugation at $690 \times g$ for $8 \mathrm{~min}$, the supernatant was discarded and the faecal pellet was re-suspended in approximately $12 \mathrm{ml}$ of saturated sodium chloride solution (specific gravity: 1.18) and centrifuged again as above. Four to five drops were then 
Table 1 Geographical distribution of farms and samples included in this study

\begin{tabular}{lll}
\hline & No. of farms & $\begin{array}{l}\text { No. of samples (no. of } \\
\text { samples examined by } \\
\text { flotation) }\end{array}$ \\
\hline North-west & 9 & $200(196)$ \\
Schleswig-Holstein & 1 & 16 \\
Lower Saxony & 3 & 55 \\
North-Rhine Westphalia & 5 & 129 \\
South-west & 6 & $130(125)$ \\
Hesse & 2 & 33 \\
Baden-Wuerttemberg & 4 & 97 \\
North-east & 9 & $222(201)$ \\
Mecklenburg-Vorpommern & 1 & 14 \\
Saxony & 6 & 166 \\
Thuringia & 2 & 42 \\
South-east & 3 & $65(65)$ \\
Bavaria & 3 & 65 \\
Total & 27 & $617(587)$ \\
\hline
\end{tabular}

removed from the surface of the suspension with a loop wire an examined under the microscope $(100 \times$ magnification) for the presence of parasite stages. Helminth eggs were recorded qualitatively and oocysts of coccidian semi-quantitatively from 1 (very low, 1-3 oocysts/sample) to 4 (high, more than 30 oocysts per sample).

A McMaster count was performed to quantify the strongylid eggs per gram of faeces (EPG). For this, $4 \mathrm{~g}$ of faeces was homogenized in approximately $15 \mathrm{ml}$ of saturated sodium chloride solution and sieved into a measuring cylinder. The flotation solution was added to a final volume of $60 \mathrm{ml}$; the suspension was mixed thoroughly in a stirring flask and immediately transferred to two McMaster counting chambers $(150 \mu \mathrm{l}$ each) and left for 5 min before examination at $100 \times$ magnification. The detection limit for EPG was 50. All animals with 150 EPG and higher were included in a faecal egg count reduction test (FECRT). The owners were informed and further instructions on treatment and the second faecal sampling were provided.

According to the results of the questionnaire, alpaca owners predominantly used monepantel, moxidectin or fenbendazole as anthelmintics. The decision on which drug was to be used in the study was based on which drugs had been recently used in the herd (this was then used for the FECRT). Monepantel (Zolvix ${ }^{\circledR}$, Elanco, Bad Homburg, Germany; $7.5 \mathrm{mg} / \mathrm{kg}$ p.o.), moxidectin (Cydectin $^{\circledR}$, Zoetis, Parsippany, NJ, USA; $0.4 \mathrm{mg} / \mathrm{kg}$ p.o.) or fenbendazole (Panacur ${ }^{\circledR}$, MSD/Intervet, Schwabenheim, Germany; $10 \mathrm{mg} / \mathrm{kg}$ p.o.) were applied according to dose recommendations for South American camelids [5, 15-17]. The animals were dosed individually based on body weight (determined by weighing or estimated by the attending veterinarian).

Individual faecal samples were collected after treatment, transferred to the laboratory and examined by McMaster counting to calculate the reduction in egg excretion.

\section{Larval cultivation}

Faecal samples collected before treatment were pooled by farm $(20-50 \mathrm{~g})$, homogenized in water and mixed with vermiculite to achieve a moist crumbly structure. The samples were kept at $25{ }^{\circ} \mathrm{C}$ for seven to ten days under daily aeration and moistening. After that, third-stage larvae were collected and differentiated microscopically (40× magnification) after staining with Lugol's solution.

\section{Statistical evaluation}

Descriptive statistics were carried out in Microsoft Excel. For calculation of the FECR and corresponding confidence intervals the program eggCounts-2.1-1' in $\mathrm{R}$ (v.3.5.0) was used [18]. Calculations were done with the standard "two sampled paired" model and the "model with individual efficacy" [19].

\section{Results}

Sample procurement and faecal consistency

Overall, 617 samples [mean of 22.9 samples/herd, standard deviation $(\mathrm{SD})=11.7$ ] from 538 animals (mean 21.1 animals/herd; $\mathrm{SD}=9.2$ ) were examined from April to November 2018. On farms with less than 20 alpacas, animals $(n=34)$ were repeatedly enrolled to receive a sufficient number of samplings per farm. Twelve alpacas did not respond to treatment (FECR $<70 \%$ after first treatment) and were treated again with a different anthelmintic. In both cases of repeated treatments, EPG values after the previous treatment were used as pre-treatment values in the FECRT.

Faecal consistency was determined for 590 samples. Of these, $50.5 \%$ were of physiological consistency (score 1), 29.3\% had soft formed faeces (score 2), 19.0\% were soft (score 3 ) and $1.7 \%$ were semi-liquid (score 4 ).

\section{Qualitative results of coproscopy}

A total of 587 samples were examined both by flotation and the McMaster technique. For 24 of these, the amount of faeces was below than the minimum required for flotation. For an additional 30 samples, only McMaster results were obtained (617 samples were examined by flotation and/or McMaster counting). The most frequently detected parasite stages were oocysts of Eimeria spp. 
- Moniezia $n$ Trichuris $\square$ Strongylids (excl. Nematodirus) $\backsim$ Nematodirus $\backsim$ Eimeria

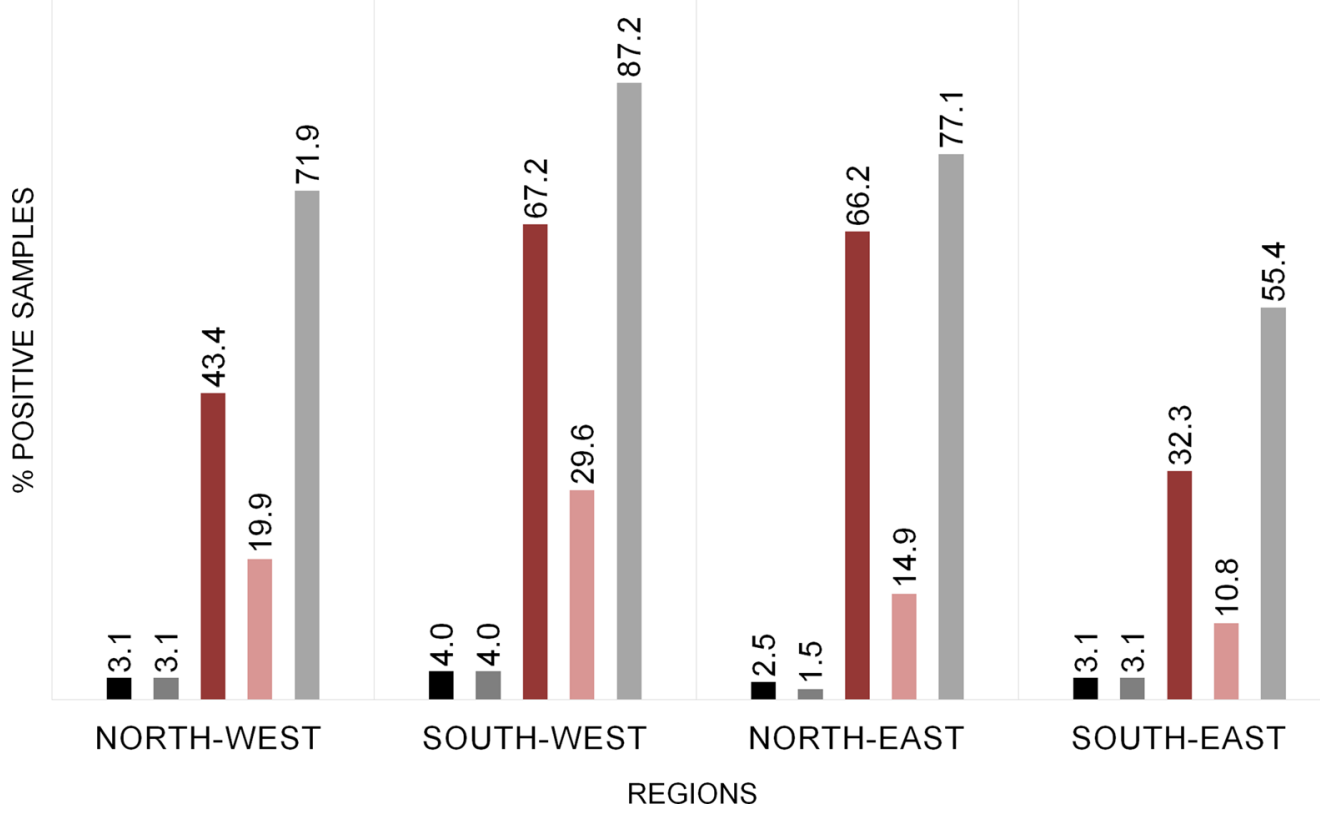

Fig. 1 Geographical distribution of prevalence rates for the endoparasites detected by flotation ( $n=587$ samples; see Table 1 for details)

(441/587 samples; $75.1 \%)$. Of these $76.9 \%$ showed a very low grade, $16.3 \%$ a low grade, $5.7 \%$ a medium grade and $1.1 \%$ a high grade of excretion. Of the helminths, strongylids were most common: $55.0 \%$ of the 587 samples examined by flotation were positive. Out of the 617 samples examined either by flotation or McMaster or both, $373(60.5 \%)$ were positive for strongylid eggs by at least one method: $41.8 \%$ were positive in both; $15.6 \%$ were positive in flotation but negative by McMaster counting; and $3.1 \%$ were negative by flotation and positive by McMaster. Nematodirus eggs were detected in $19.3 \%$ of the samples, cestode eggs in $3.1 \%$ and Trichuris eggs in $2.7 \%$ of the samples examined by flotation. Regarding the geographical distribution of the different parasites in the samples, minor variations in prevalence rates could be seen but the parasites detected were found in all regions of Germany (Fig. 1).

In the 587 samples examined by flotation, no correlation between faecal score/diarrhoea and excretion of strongylid eggs or coccidia oocysts could be determined (details not shown). Two of the 27 farms enrolled did not provide samples positive for strongylids, and larval cultures from another two farms with positive samples in flotation did not yield larvae. In the remaining 23 pooled
Table 2 Results of larval cultures from pooled faecal samples by farm ( $n=23$ pooled samples which yielded positive results)

\begin{tabular}{ll}
\hline Detected strongylid genera and mixed infections & \% positive farms \\
\hline Strongylid genus present & \\
Haemonchus & 87.0 \\
Cooperia & 43.5 \\
Trichostrongylus & 21.7 \\
Ostertagia & 13.0 \\
Nematodirus & 4.3 \\
Oesophagostomum & 4.3 \\
Number of genera present & \\
1 & 43.5 \\
2 & 30.4 \\
3 & 17.4 \\
4 & 4.3 \\
\hline
\end{tabular}

farm samples, Haemonchus was detected most frequently (Table 2).

\section{Faecal egg count reduction test}

A total of 617 pre-treatment samples were examined by McMaster counting, and $49.9 \%$ were positive. The mean EPG ( \pm standard deviation, SD) of all samples 
was $114.0 \pm 251.5$, with a maximum of 2650 EPG. In 215 samples (34.8\%) EPG values were 150 or higher, and in 208 of the latter cases, treatment was carried out and a second sample could be obtained. The mean body weight $( \pm S D)$ of these animals was $58.6 \pm 13.8 \mathrm{~kg}$ (median, $60.0 \mathrm{~kg}$; minimum, $21.9 \mathrm{~kg}$; maximum, $100.0 \mathrm{~kg}$ ), and animals were dosed by weight. The average number of days between treatment and the second sampling was $16.3 \pm 1.6$ (minimum, 13 days; maximum, 25 days). Between 66 and 71 samples were examined after treatment with either fenbendazole, moxidectin or monepantel. Overall, $67.5 \%$ of the samples were negative in the McMaster examination after treatment (Table 3), most of which were in the moxidectin and monepantel treated groups.

Repeated treatment with change of the anthelmintic drug was conducted in 25 animals; one of them received all three different drugs consecutively due to insufficient FECR (see below). At the first treatment, 22 of these animals received fenbendazole and three moxidectin. The animals treated with fenbendazole as a first treatment received either moxidectin $(n=18)$ or monepantel $(n=4)$ as a second treatment. Moxidectin application resulted in 17 negative results. One animal still had a persisting EPG of 800, was re-treated with monepantel and became negative after that. Monepantel as a second treatment resulted in 7/8 negative results and one with an EPG of 150. The animals that were still positive after moxidectin as a first treatment all received monepantel. Two weeks later, two of them had a negative faecal egg count and one had an EPG of 150.

When all animals in each treatment group were combined and analysed in the two samples paired model, the fenbendazole-treated group displayed an average FECR of $45 \%$. For the moxidectin-treated group the calculated FECR was 92\%, and in the monepantel-treated group $96 \%$. When the model was applied taking individual efficacy into consideration, fenbendazole treatment had an efficacy of $62 \%$, moxidectin and monepantel of $100 \%$ (Table 3).

At the herd level, the farms which used fenbendazole showed treatment efficacies of $15-87 \%(41-79 \%$ when individual efficacy was considered). The farms under moxidectin treatment had FECR rates of $30-100 \%$ (60$100 \%$ with individual efficacy consideration) and the farms with monepantel treatment showed 73-99\% FECR (86-99\% with individual efficacy consideration) (Fig. 2).

Haemonchus larvae were found in pre-treatment samples on all farms $(n=9)$ with poor FECR (defined as farms with a FECR $<100 \%$ in $>10 \%$ of the samples). Cooperia larvae were detected on six of these farms, Trichostrongylus on four; all three genera were overrepresented on these farms (Fig. 3). Farms with a poor FECR were found in all areas of Germany (north-west: 3/9, south-west: 2/6, north-east: 4/9 farms) except the south-east (Bavaria; 3 farms).

\section{Discussion \\ Coproscopical results}

Endoparasitoses are a common problem in the South American camelids. Losses in alpacas in Peru due to nematode infections of the gastrointestinal tract are estimated to be $46.3 \%$ of the total losses [20]. In the present study, coccidia (genus Eimeria) were the most common endoparasites detected. In South American camelids, five different Eimeria species (E. alpacae, E. lamae, E. punoensis, E. macusaniensis and rarely E. ivitaenis) can be found $[5,21]$; E. peruviana is currently not validated as a species. Especially E. macusaniensis is frequently implemented in clinical cases [21-23]. Due to the high host specificity Eimeria spp. are not transmitted between South American camelids and other species [21, 22]. As we examined only animals older than one year we found mostly very low or low excretion densities; however, in some cases animals shed considerable amounts of oocysts, indicating that coccidiosis may occur in alpacas

Table 3 Results of the faecal egg count reduction test (FECRT)

\begin{tabular}{|c|c|c|c|}
\hline & Fenbendazole & Moxidectin & Monepantel \\
\hline No. of herds ${ }^{a}$ & 12 & 12 & 10 \\
\hline No. of samples & 71 & 71 & 66 \\
\hline Average EPG before treatment $\pm S D$ & $324.6 \pm 387.6$ & $312.7 \pm 378.0$ & $280.3 \pm 311.1$ \\
\hline Average EPG after treatment $\pm S D$ & $178.2 \pm 359.7$ & $23.9 \pm 103.1$ & $11.4 \pm 43.7$ \\
\hline$\%$ of samples with $E P G=0$ after treatment & 26.8 & 87.3 & 90.9 \\
\hline $\begin{array}{l}\text { No. of farms with EPG }>0 \text { (No. of farms with }>10 \% \text { of samples with EPG } \\
>0 \text { ) }\end{array}$ & $12(8)$ & $6(4)$ & $2(0)$ \\
\hline FECR in \% (95\% uncertainty interval) & $45(35-52)$ & $92(89-95)$ & $96(93-98)$ \\
\hline FECR in \% (individual efficacy) (95\% uncertainty interval) & $62(48-73)$ & $100(99-100)$ & $100(98-100)$ \\
\hline
\end{tabular}

a Sum $>27$, since some farms used different compounds

Abbreviation: SD, standard deviation 

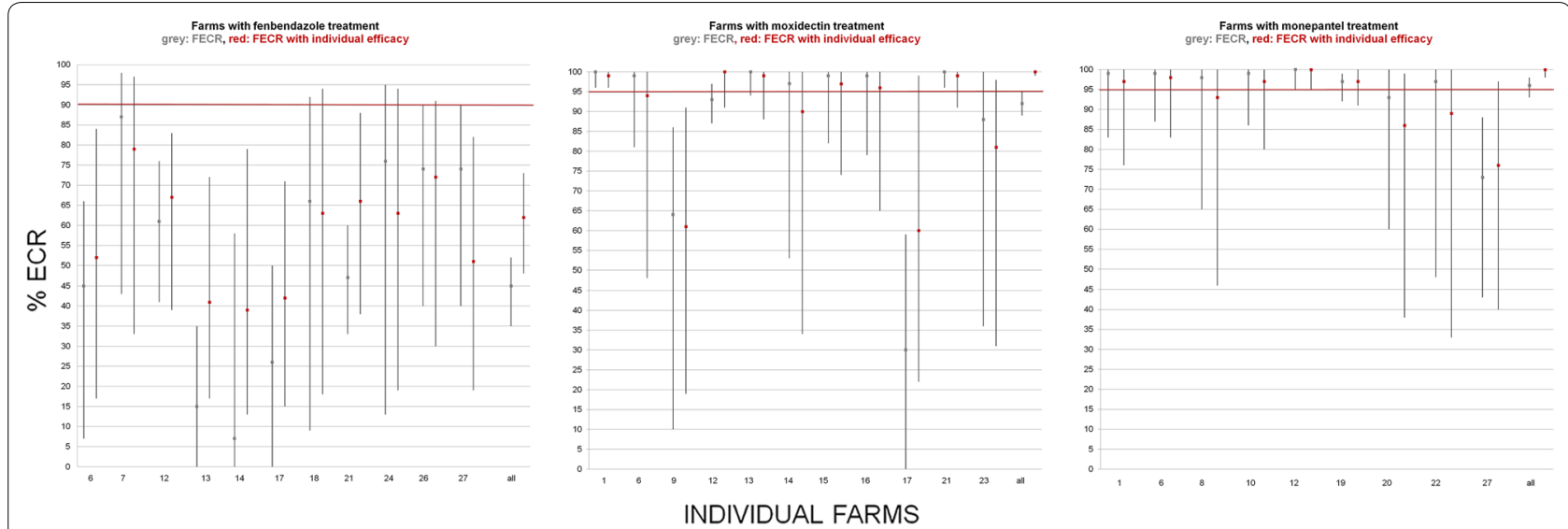

Fig. 2 Faecal egg count reductions (mean and confidence intervals) for individual farms for three different anthelmintic drugs used. Horizontal red lines show the expected level of susceptibility

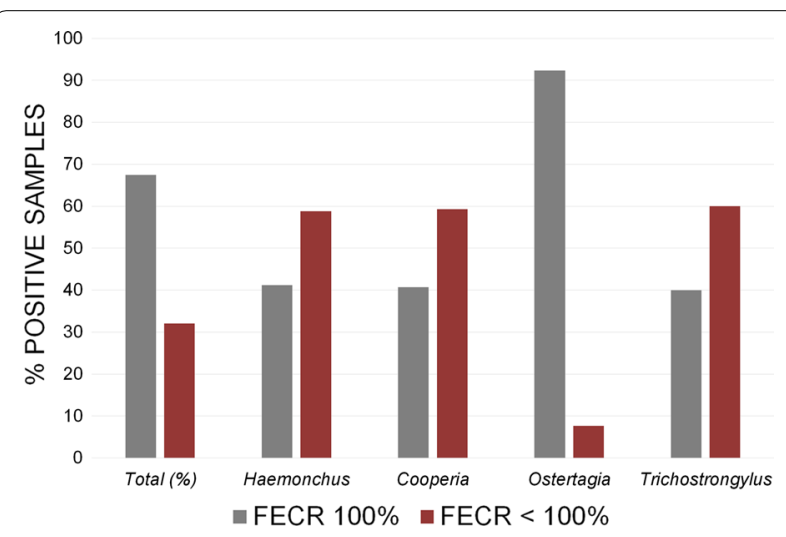

Fig. 3 Relative composition of strongylid genera before treatment in relation to samples with faecal egg count reduction (FECR) of $100 \%$ vs FECR of $<100 \%$

under unfavourable conditions on the farm or might be facilitated by a poor immune status of the animals.

In South American camelids different gastrointestinal strongylids can be found [5, 24-26]. In addition to host-specific species, South American camelids can also be infected with strongylid species of Old World camelids (Camelostrongylus mentulatus) as well as species of wild and domestic ruminants [5]. Of the camelid-specific nematodes, Spiculopteragia peruvians is so far only known to occur in South America [5] and Graphinema aucheniae in South America and Australia [26] while Lamanema chavezi has also been detected in llamas in New Zealand [27] and the USA [28]. The latter is rather pathogenic to the camelid host as its enterohepatic migration induces hemorrhagic enteritis and hepatitis [29]. There is no indication of its occurrence so far in Europe; however, Lamanema eggs are similar to those of Nematodirus and can only reliably be differentiated by molecular tools [30]. Both can easily be missed in flotation due to their high density [31], so special attention must be paid on this strongylid species. Recently, the first infection with the camelid-specific Nematodirus lamae in Europe was reported from the UK in a case of sudden death of an alpaca [32] and the authors pointed out that moving of animals is of high importance in spreading parasites to new areas. The genus Nematodirus is commonly reported from both domesticated and wild South American camelids. Besides $N$. lamae, species infecting ruminants (Nematodirus abnormalis, $N$. battus, $N$. filicollis, $N$. helvetianus, $N$. spathiger) can also be found in South American camelids [5, 26, 33-36]. Nematodirus was detected in 19.3\% of the alpaca samples, making this genus the third-most common parasite in the examined population. The eggs of Nematodirus are easily differentiated from those of the families Trichostrongylidae or Chabertiidae and were not considered in the faecal egg count reduction test. The ruminant strongylids Ostertagia ostertagi, $O$. lyrata, Teladorsagia circumcincta, Marshallagia marshalli, Haemonchus contortus, Trichostrongylus axei, T. colubriformis, T. longispicularis, T. vitrinus, Cooperia oncophora, C. pectinata, C. punctata, Bunostomum trigonophorum, Oesophagostomum columbianum, $O$. venulosum and Chabertia ovina can also infect South American camelids [5, 7, 11, 25, 26, 35-39]. Depending on the worm burden, the nematode species involved and the age and constitution of the host animal, nematode infection can lead to different degrees of disease progression, from subclinical and mild disease with unspecific signs, like decreased appetite, emaciation and dull coat, to severe cases with diarrhoea, apathy, hypoalbuminemia and anaemia [6].

Of the strongylids transmitted from small ruminants, $H$. contortus probably plays the most significant role in 
the South American camelids and accounts for the greatest losses due to endoparasitoses [40]. A recent study from Australia confirmed the high infection rates and worm burdens for $H$. contortus in alpacas [26].

Whipworms (Trichuris barbetonensis, T. cameli, T. discolor, T. globulosa, T. ovis, T. skrjabini, T. tenuis, T. tumens) are relatively common parasites of South American camelids as well as ruminants $[25,26,39]$ as re-infections with the long-lived and highly resistant larvated eggs are common [23]. Trichuris eggs were found in only $5.7 \%$ of the samples, which may be an underestimate, as these eggs require a higher density of flotation solution to reliably be detected in flotation. This must also be assumed for the large Nematodirus eggs and the thickshelled oocysts of Eimeria macusaniensis [41].

Tapeworms of three genera can occur in alpacas: Moniezia (M. expansa, M. benedeni), Thysaniezia (T. ovilla) and Thysanosoma (T. actinioides) [20, 23, 38, 42-48]. Moniezia infections have been reported in South American camelids from central Germany [23] and identified as M. expansa and M. benedeni in Switzerland [49]. Although none of the used drugs in this study is effective against cestodes in alpacas (except fenbendazole which requires doses of $50 \mathrm{mg} / \mathrm{kg} \mathrm{BW}$; [5]), the infection rate in the present study was low (3.1\%) and these parasites seem to be generally rare in South American camelids [23], so little is known about their pathogenicity.

\section{Faecal egg count reduction test}

Only animals with a pre-treatment faecal egg count of 150 EPG or higher were included in the treatment. South American camelids generally appear to shed relatively low numbers of gastrointestinal nematode eggs, which may be due to a lower infection pressure as these animals do not spread their faeces across pasture but deposit them in specific places ("latrines"; $[33,50])$. In addition, they seem to be less susceptible to the nematodes of small ruminants and consequently excrete fewer eggs [51, 52].

In the case of fenbendazole, $73.2 \%$ of the animals still excreted eggs after treatment. After treatment with moxidectin, eggs could still be detected in the faeces of $12.7 \%$ of the samples, and after monepantel treatment, 9.1\% of the animals were still positive upon the second faecal examination. Fenbendazole had by far the lowest efficacy. Even when an efficacy of only $90 \%$ is expected [53], only one additional sample and none of the farms met this cutoff. For moxidectin and monepantel, efficacy was generally high but single animals and farms clearly showed persistent egg excretion. It is unclear whether this is sign of anthelmintic resistance of the worms involved or due to poor bioavailability of these drugs in alpacas $[6,54]$. In a previous study in the USA, fenbendazole was used to treat alpacas with $10 \mathrm{mg} / \mathrm{kg}$ of body weight and the
FECRT revealed a complete lack of efficacy [55]. The authors concluded that this was due to resistance; however, no confirmatory in vitro study was carried out. Additional tests have to be conducted to unambiguously determine anthelmintic resistance, such as the composition of strongylid genera post treatment (unfortunately, this could not be established in the present study due to technical constraints) and assays for further evaluation of susceptibility of the nematodes to the applied drugs [55]. The recommended doses for small ruminants were previously simply transferred to the South American camelids. However, the latter can display very different pharmacokinetic drug profiles, e.g. for fenbendazole two to four times the doses for sheep are recommended [16, 17], and for monepantel three times the dose recommended for sheep is necessary to achieve a sufficient egg count reduction [15]. Underdosing of anthelmintics not only leads to poor reduction of the worm burden, it can also drive the development of resistance in camelid nematodes [6]. If this is the case on alpaca farms, the emergence of anthelmintic resistance (especially against fenbendazole) is currently significantly promoted. Underdosing due to body weight underestimation (which can largely be excluded in the present study since weighing scales were used in a number of farms and one of the authors, LK, provided assistance in correct weight determination) or due to incomplete swallowing of the drug (which South American camelids are prone to because of spitting) can contribute to this problem on the farms.

Infections with gastrointestinal strongylids mostly take place on pasture and many species can undergo hypobiosis in the mucosal layer of the intestinal wall in the winter months to be reactivated in spring, so that during this time, anthelmintic treatment is frequently unsuccessful [33]. To rule out this source of error for this study, the investigations took place in the period from April to October.

The FECRT is difficult to interpret in terms of anthelmintic resistance since egg excretion was low in most cases and studies evaluating the actual efficacy of different doses of anthelmintic drugs in alpacas (including determination of effective doses by titration and determination of dose-limiting parasite species; see $[55,56])$ are not available. However, the high number of treatment failures especially after fenbendazole application (24/71 samples had a FECR of $<50 \%$ after treatment) versus complete cessation of egg excretion (19/71 samples had a FECR of $100 \%$ ) indicates considerable variations in the susceptibility of the different strongylid populations to treatment with different anthelmintics. This reflects the owners' concern noticed in the questionnaire survey conducted previously [4] where $15 \%$ of the owners suspected unsatisfactory efficacy of anthelmintic treatment. 
However, there was only an incomplete alignment of the owners' perception with the results of the test; of the 17 farms which had FECR results $<100 \%$, only six (35.3\%) reported poor efficacy or losses due to endoparasites, while one of the ten farms with complete FECR had indicated reduced efficacy in the questionnaire [4].

Taking geographical differences or farm structures into consideration, cases of insufficient FECR were found all over Germany. In general, the investigated herds were all medium to large as defined previously [4] with a minimum of 11 alpacas per farm, but on small farms the numbers of available samples were limited, so data from these farms need to be interpreted with caution. A FECR $<100 \%$ was seen in one or two samples/farm in ten cases (three of them from farms with a limited sample size); on six farms with a FECR $<100 \%$ the percentage of affected samples ranged from 16.9 to $37.5 \%$ (5-11 samples/farm) and involved treatment with all three drugs overall. Since the used dosages were adapted to alpacas $[5,15-17]$ and were sufficient to reduce egg excretion in $26.8,87.3$ and $90.9 \%$ of the animals after fenbendazole, moxidectin or monepantel treatment, respectively, general underdosing is unlikely. Although more detailed studies will be required to unequivocally determine the presence and extent of resistance of the investigated nematode populations against the applied anthelmintic compounds, indirect evidence supports the assumption that the efficacy of the anthelmintic treatment applied in this study may already be compromised in the examined alpaca herds. The larval cultures revealed the presence of nematodes of small ruminant origin, and for these strongylids resistance against benzimidazoles, levamisole or moxidectin has been shown in a number of studies from Germany [57-62] and neighbouring countries such as Switzerland [49, 61, 63], Austria [64, 65], Belgium [14] and the Netherlands [66]. Furthermore, in the UK monepantel resistance has lately been reported [67], so it must be assumed that transmission of strongylids from small ruminants to South American camelids may also include resistant populations. In Peru, anthelmintic resistance to benzimidazoles and macrocyclic lactones has been reported in trichostrongylids of alpacas [68, 69], and in Australia, resistance in strongylids (primarily Haemonchus, Trichostrongylus, Camelostrongylus, Ostertagia and Cooperia) of alpacas against ivermectin, fenbendazole, closantel and moxidectin has been described [13].

In addition, in most studies on anthelmintic resistance, $H$. contortus has been implicated as a major driver (e.g. [11, 14]), and this nematode was the most abundant in the larval cultures examined in this study, although it was previously considered to be less frequent in New Wold camelids than in small ruminants $[44,50,70]$. We confirm that $H$. contortus is a common strongylid species of South American camelids, and we further hypothesize that this high representation of the Barber's Pole worm in the examined samples was promoted by the presence of resistant worms of this species. To a lesser extent this also applies to Cooperia and Trichostrongylus which have also been inferred in anthelmintic resistance in camelids $[11,12,14,68]$. Since $H$. contortus is not only pathogenic in small ruminants but also in South American camelids $[8,26,40]$, the presence of this species and its response to anthelmintic treatment should be monitored thoroughly, especially in view of cross-transmission between ruminants and alpacas as described to be considerable in recent studies from Australia [26]. Co-grazing could not be identified as a risk factor in the present study since it was not practiced on any of the examined farms (although on one farm after-use of pasture by goats was reported; this farm was not included in the FECRT due to low/negative McMaster results). In addition, C. oncophora is the dose-limiting species in anthelmintic efficacy in cattle [71] so this species could benefit from the low doses of anthelmintic applied.

\section{Conclusions}

The present study confirms that gastrointestinal strongylids are common parasites in German alpaca herds and animals frequently excrete eggs of these nematodes, although mostly in lower amounts compared to small ruminants. Only two of the 27 examined farms provided samples negative for gastrointestinal strongylids. Haemonchus was the most prevalent genus, indicating that previous anthelmintic treatments may have been insufficient to eliminate it effectively. Fenbendazole was not sufficiently effective at the dose recommended for South American camelids, and the possibility of resistance development cannot be ruled out. Although moxidectin and monepantel had an overall satisfactory efficacy, it was reduced on some farms. Again, a possible establishment of resistant parasites transferred from small ruminants cannot be excluded. Despite the limitations of the FECR for samples with generally low egg excretion, the results highlight the importance of faecal examinations for monitoring of the infection status of the herd and an indication of treatment necessity and success. In addition, correct dosing is mandatory to maintain treatment success and efficacy. Frequent deworming of all animals in a herd must be considered obsolete as it promotes resistance through strong selection pressure [71, 72]. In line with other domestic animal species, adequate control of strongylid infections in South American camelids requires monitoring of faecal egg shedding, selective (ideally, targeted selective) treatment and post-treatment coproscopical examination to evaluate treatment success, 


\section{as well as clinical observations of the animals for signs of parasitic disease.}

\author{
Abbreviations \\ FECRT: faecal egg count reduction test; EPG: eggs per gram of faeces; SD: \\ standard deviation.
}

\section{Acknowledgements}

The authors gratefully acknowledge the cooperation of the alpaca owners who participated in this study.

\section{Authors' contributions}

LK, AJ and TW designed the study and drafted the manuscript. LK organised the study, contacted the owners and examined the samples. $\mathrm{BH}$ analysed the FECRT data. RS prepared and analysed the larval cultures. All authors read and approved the final manuscript.

\section{Funding}

The study was organisationally and financially supported by the German alpaca breeder organisation Alpaca Association e.V.

\section{Availability of data and materials}

All data generated or analysed during this study are included in this published article.

\section{Ethics approval and consent to participate}

This study was approved by the institutional Ethics Committee of the Vetmeduni Vienna.

\section{Consent for publication}

Not applicable.

\section{Competing interests}

The authors declare that they have no competing interests.

\begin{abstract}
Author details
${ }^{1}$ University Clinic for Ruminants, Department for Farm Animals and Veterinary Public Health, University of Veterinary Medicine Vienna, Veterinärplatz 1 1210 Wien, Austria. ${ }^{2}$ Institute of Parasitology, Department of Pathobiology, University of Veterinary Medicine Vienna, Veterinärplatz 1, 1210 Wien, Austria. ${ }^{3}$ Institute of Parasitology, Faculty of Veterinary Medicine, University of Leipzig, An den Tierkliniken 35, 04103 Leipzig, Germany.
\end{abstract}

Received: 21 March 2019 Accepted: 27 June 2019

Published online: 02 July 2019

\section{References}

1. Anderson DE, Whitehead CE. Alpaca and Ilama health management. Preface. Vet Clin North Am Food Anim Pract. 2009;25:xi-xii.

2. Hengrave Burri I, Martig J, Sager H, Liesegang A, Meylan M. Neuweltkameliden in der Schweiz. I. Population, Haltung und Gesundheitsprobleme. Schweiz Arch Tierheilkd. 2005;147:325-34.

3. Gauly M, Vaughan J, Cebra C. Neuweltkameliden: Haltung, Zucht, Erkrankungen. 4th ed. Stuttgart: Thieme; 2018.

4. Kultscher L, Joachim A, Wittek T. Untersuchung zum Auftreten und Management von Endoparasiten bei Alpakas in Deutschland und Österreich. Tierärztl Praxis G. 2018;46:241-8.

5. Ballweber LR. Ecto- and endoparasites of New World camelids. Vet Clin North Am Food Anim Pract. 2009;25:295-310.

6. Franz S, Wittek T, Joachim A, Hinney B, Dadak AM. Llamas and alpacas in Europe: endoparasites of the digestive tract and their pharmacotherapeutic control. Vet J. 2015;204:255-62.

7. Schlögl C. Erhebungen zum Vorkommen von Endo- sowie Ektoparasiten bei Neuweltkameliden. Thesis, Veterinary Faculty, Ludwig Maximilians University Munich, Germany; 2010
8. Goerigk D, Jirasek A, Fürll M. Endoparasiten bei Neuweltkameliden. Klauentierpraxis. 2013;3:29-33.

9. Theuß T, Goerigk D, Rasenberger S, Starke A, Schoon H-A. Sektionsbefunde von Neuweltkameliden-Eine retrospektive Analyse des Sektionsgutes des Leipziger Instituts für Veterinär-Pathologie. Tierärztl Praxis G. 2014;42:278-88.

10. Lambacher B, Wittek T, Joachim A, Dadak A, Stanitznig A, Hinney B, et al. From the New World to the Old World: endoparasites of South American camelids in Austria. Wien Tierärztl Monatsschr. 2016;103:33-42.

11. Jabbar A, Campbell AJD, Charles JA, Gasser RB. First report of anthelmintic resistance in Haemonchus contortus in alpacas in Australia. Parasit Vectors. 2013;6:243

12. Rashid MH, Vaughan JL, Stevenson MA, Campbell AJD, Beveridge I, Jabbar A. Anthelmintic resistance in gastrointestinal nematodes of alpacas (Vicugna pacos) in Australia. Parasit Vectors. 2018;11:388.

13. Rashid MH, Vaughan JL, Stevenson MA, Campbell AJD, Saeed MA, Indjein $L$, et al. Epidemiology of gastrointestinal nematodes of alpacas in Australia: I. A cross-sectional study. Parasitol Res. 2019;118:891-900.

14. Sarre C, Claerebout E, Vercruysse J, Levecke B, Geldhof P, Pardon B, et al. Doramectin resistance in Haemonchus contortus on an alpaca farm in Belgium. Vet Parasitol. 2012;185:346-51.

15. Dadak AM, Asanger H, Tichy A, Franz S. Establishing an efficacious dose rate of monepantel for treating gastrointestinal nematodes in llamas under field conditions. Vet Rec. 2013;172:155.

16. Emmerich IU, Ganter M, WittekT. Dosierungsvorschläge für Arzneimittel bei kleinen Wiederkäuern und Neuweltkameliden. Hannover: Schattauer; 2016.

17. Walker PG. Medications for camelids; 2019. https://icinfo.org/sites/camel id-sta.osumc.edu/files/documents/medicationsdosages3_25_13.pdf. Accessed 10 Mar 2019.

18. Torgerson PR, Paul M, Furrer R. Evaluating faecal egg count reduction using a specifically designed package 'eggCounts' in R and a user friendly web interface. Vet Parasitol. 2014;44:299-303.

19. Wang C, Torgerson PR, Kaplan RM, George MM, Furrer R. Modelling anthelmintic resistance by extending eggCounts package to allow individual efficacy. Int J Parasitol Drugs Drug Resist. 2018;8:386-93.

20. Leguía G. The epidemiology and economic impact of llama parasites Parasitol Today. 1991;7:54-6.

21. Dubey JP. A review of coccidiosis in South American camelids. Parasitol Res. 2018;117:1999-2013.

22. Palacios CA, Perales RA, Chavera AE, Lopez MT, Braga WU, Moro M. Eimeria macusaniensis and Eimeria ivitaensis co-infection in fatal cases of diarrhoea in young alpacas (Lama pacos) in Peru. Vet Rec. 2006;158:344-5.

23. Schmäschke R. Endo- und Ektoparasiten bei Neuweltkameliden und ihre Bekämpfung. Tierärztl Praxis G. 2015;43:169-79.

24. Puicón V, Chávez J, Gutiérrez G. Prevalencia de nematodos gastrointestinales en alpacas y ovinos de dos cooperativas comunales de la región Pasco, Perú. Rev Inv Vet Perú. 2018;29:1440-8.

25. Mehlhorn H. Nematodes of camels. In: Mehlhorn H, editor. Encyclopedia of parasitology. Berlin-Heidelberg: Springer; 2015.

26. Rashid $\mathrm{MH}$, Beveridge I, Vaughan $\mathrm{J}$, Jabbar A. Worm burdens and associated histopathological changes caused by gastrointestinal nematodes in alpacas from Australia. Parasitol Res. 2019;118:1031-8.

27. McKenna PB, Morley C, Koning M, Tahana JS, Taylor MJ. Confirmation of the occurrence of the nematode parasite Lamanema chavezi Becklund, 1963 in South American camelids in New Zealand. N Z Vet J. 2009:57:395-6.

28. Jarvinen JA, Whitley EM, Kreuder AJ, Schleining JA. Identification of Lamanema chavezi Becklund 1963 infection in a llama (Lama glama) in the United States. J Vet Diagn Invest. 2014;26:178-83.

29. Cafrune MM, Aguirre DH, Rickard LG. First report of Lamanema chavezi (Nematoda: Trichostrongyloidea) in llamas (Lama glama) from Argentina. Vet Parasitol. 2001;97:165-8.

30. Petrigh RS, Cafrune MM, Fugassa MH. First mitochondrial and nuclear DNA sequences of Lamanema chavezi (Nematoda: Molineidae): novel findings to improve its identification in feces from South American camelids. Parasitol Int. 2019;68:60-2.

31. Cafrune MM, Marín RE, Rigalt FA, Romero SR, Aguirre DH. Lamanema chavezi (Nematoda: Molineidae): epidemiological data of the infection 
in South American camelids of Northwest Argentina. Vet Parasitol. 2009;166:321-5

32. Mitchell S, Hopkins B. Nematodirus lamae identified in an alpaca in the UK. Vet Rec. 2016;178:271-2.

33. Rohbeck S. Parasitosen des Verdauungstrakts und der Atemwege bei Neuweltkameliden—Untersuchungen zu ihrer Epidemiologie und Bekämpfung in einer südhessischen Herde sowie zur Biologie von Eimeria macusaniensis. Thesis, Veterinary Faculty, Justus Liebig University Gießen, Germany; 2006.

34. Correa L, Zapata B, Soto-Gamboa M. Gastrointestinal and blood parasite determination in the guanaco (Lama guanicoe) under semi-captivity conditions. Trop Anim Health Prod. 2012;44:11-5.

35. Hyuga A, Matsumoto J. A survey of gastrointestinal parasites of alpacas (Vicugna pacos) raised in Japan. J Vet Med Sci. 2016;78:719-21.

36. Pichler V. Endoparasiten von Neuweltkameliden in Niederösterreich und der Steiermark. Thesis, University of Veterinary Medicine Vienna, Austria; 2010

37. Loiseaux, JL. Évaluation de la présence des nématodes gastro-intestinaux et des agents de la gale chez les petits camélidés en France et essai thérapeutique sur la gale des alpagas du sud du Perou. Thesis, École nationale vétérinaire d'Alfort, France; 1992.

38. Fowler M. Medicine and surgery of camelids. 3rd ed. Oxford: Blackwell; 2010

39. Ortiz P. Gastrointestinal and hepatic parasites affecting Alpacas (Lama pacos) and vicuñas (Vicugna vicugna) in Cajamarca, Perú. In: 24th International Conference of W.A.A.V.P., Perth, Australia, 2013.

40. Edwards EE, Garner BC, Williamson LH, Storey BE, Sakamoto K. Pathology of Haemonchus contortus in New World camelids in the southeastern United States: a retrospective review. J Vet Diagn Invest. 2016;28:105-9.

41. Cebra CK, Stang BV. Comparison of methods to detect gastrointestinal parasites in llamas and alpacas. J Am Vet Med Assoc. 2008;232:733-41.

42. Chavez C, Guerrero C. Ecto y endoparasitos identificados en el Departmento de Parasitologia de la Facultad de Medicina Veterinaria (1947-1960). Rev Fac Med Vet Lima. 1960;15:45-68.

43. Aguirre DH, Cafrune MM. Parasitosis de los camélidos Sudamericanos. In: Suarez VH, Olaechea FV, Rossanigo CE, Romero JR, editors. Enfermedades parasitarias de los ovinos y otros rumiantes menores en el Cono Sur de América. Anguil: Ediciones INTA; 2007.

44. Rickard LG, Bishop LK. Helminth parasites of Ilamas (Lama glama) in the Pacific Northwest. J Helminthol Soc Wash. 1991;58:110-5.

45. McKenna PB. Register of new host-parasite records. Surveillance. 2003:30:12-3.

46. McKenna PB. Register of new host-parasite records. Surveillance. 2003;30:15-6.

47. Beldomenico PM, Uhart M, Bono MF, Marull C, Baldi R, Peralta JL. Internal parasites of free-ranging guanacos from Patagonia. Vet Parasitol. 2003;118:71-7.

48. Taylor MA, Coop RL, Wall RL. Veterinary parasitology. 3rd ed. Oxford: Blackwell; 2007. p. 68

49. Hertzberg H, Bauer C. Anthelmintic resistance in gastrointestinal Strongylidae in sheep and goats: new data on prevalence, epidemiology, preventive measures and alternatives to anthelmintic drugs. Berl Münch Tierärztl Wochenschr. 2000:113:122-8.

50. Carmichael IH. Internal parasitism in Australian alpacas. In: Proceedings of the Australian Alpaca Association National Conference Adelaide, Australia, 2014; 2014. p. 13-28.

51. Hill FI, Death AF, Wyeth TK. Nematode burdens of alpacas sharing grazing with sheep in New Zealand. N Z Vet J. 1993:41:205-8.

52. Green RS, Douch PG, Hill FI, Death AF, Wyeth TK, Donaghy MJ. Antibody responses of grazing alpacas (Lama pacos) in New Zealand to intestinal nematodes. Int J Parasitol. 1996;26:429-35.

53. Presidente PJA. Methods for detection of resistance to anthelmintics. In: Waller PJ, Anderson N, editors. Resistance in nematodes to anthelmintic drugs. Glebe: CSIRO; 1985. p. 13-28.
54. Galvan N, Middleton JR, Nagy DW, Schultz LG, Schaeffer JW. Anthelmintic resistance in a herd of alpacas (Vicugna pacos). Can Vet J. 2012;53:1310-3.

55. Vercruysse J, Holdsworth P, Letonja T, Barth D, Conder G, Hamamoto K, et al. International harmonisation of anthelmintic efficacy guidelines. Vet Parasitol. 2001:96:171-93.

56. Wood IB, Amaral NK, Bairden K, Duncan JL, Kassai T, Malone JB, et al. World association for the advancement of veterinary parasitology (W.A.A.V.P.) second edition of guidelines for evaluating the efficacy of anthelmintics in ruminants (bovine, ovine, caprine). Vet Parasitol. 1995;58:181-213

57. Bauer C, Fiege N, Klatte D, Enninga J, Burger HJ. Felduntersuchung zur Anthelmintikaresistenz von Trichostrongyliden in hessischen Schafherden. Berl Münch Tierärztl Wochenschr. 1988;101:185-9.

58. Moritz El. Ein Beitrag zum Befall mit Endoparasiten und zum Nachweis von Benzimidazolresistenzen bei Magen-Darm-Strongyliden der Schafe in Niedersachsen. Thesis, University of Veterinary Medicine Vienna, Austria; 2005 .

59. Bauer C. Multispecific resistance of trichostrongyles to benzimidazoles in a goat herd in Germany. Dtsch TierärztI Wochenschr. 2011;108:49-50.

60. Perbix C. Die Resistenzlage von Magen-Darm-Stronmgyliden gegenüber Moxidectin in deutschen Schafherden. Thesis, University of Veterinary Medicine Hannover, Germany; 2008.

61. Scheuerle MC, Mahling M, Pfister K. Anthelminthic resistance of Haemonchus contortus in small ruminants in Switzerland and Southern Germany. Wien Klin Wochenschr. 2009;121(Suppl. 3):46-9.

62. Voigt K, Scheuerle M, Hamel D, Pfister K. Hohe perinatale Sterblichkeit in einer Schafherde im Zusammenhang mit Dreifach-Anthelminthikaresistenz. Ein Fallbericht. Tierärztl Praxis G. 2012;40:107-11.

63. Hertzberg H, Rossmann J, Kohler L, Willi U. Vorkommen von Benzimidazol-Resistenzen bei Magen-Darmnematoden des Schafes und der Ziege in der Schweiz. Wien Tierärztl Monatsschr. 2000;87:3-9.

64. Biermayer W. Untersuchungen zur Bestimmung der Resistenzsituation von ovinen Magen-Darmstrongyliden im Bundesland Salzburg. Thesis, University of Veterinary Medicine Vienna, Austria; 1996.

65. Schoiswohl J, Hinney B, Tichy A, Bauer A, Joachim A, Krametter-Frötscher R. Suspected resistance against moxidectin in sheep strongylid nematodes in Austria. J Pharm Pharmacol. 2017;5:109-17.

66. Ploeger HW, Everts RR. Alarming levels of anthelmintic resistance against gastrointestinal nematodes in sheep in the Netherlands. Vet Parasitol. 2018;262:11-5.

67. Hamer K, Bartley D, Jennings A, Morrison A, Sargison N. Lack of efficacy of monepantel against trichostrongyle nematodes in a UK sheep flock. Vet Parasitol. 2018;257:48-53.

68. Cabrera González, MA. Resistencia de nematodos gastrointestinales de la familia "Trichostrongylidae" de las alpacas a los antihelmínticos en el centro y sur del Perú. Thesis, Universidad de León, Spain; 2008.

69. Traverso ACM. Determinación de resistencia antihelmíntica frente a ivermectina de nematodos gastrointestinales en alpacas (Vicugna pacos) Puno-Perú. Abanico Vet. 2011:1:11-20.

70. Contreras NS, Chávez AV, Pinedo RV, Leyva VV, Suárez FA. Helmintiasis en alpacas (Vicugna pacos) de dos comunidades de Macusani, Puno, durante la época seca. Rev Investig Vet Perú. 2014;25:268-75.

71. Sutherland IA, Leathwick DM. Anthelmintic resistance in nematode parasites of cattle: a global issue? Trends Parasitol. 2011;27:176-81.

72. Charlier J, Morgan ER, Rinaldi L, van Dijk L, Demeler J, Höglund J, et al. Practices to optimise gastrointestinal nematode control on sheep, goat and cattle farms in Europe using targeted (selective) treatments. Vet Rec. 2014:175:250-5.

\section{Publisher's Note}

Springer Nature remains neutral with regard to jurisdictional claims in published maps and institutional affiliations. 